\title{
EXISTENCE AND UNIQUENESS OF FORCED CONVECTIVE FLOW THROUGH A CHANNEL WITH PERMEABLE WALLS IN PRESENCE OF HEAT GENERATION
}

\author{
Ajala O.A, Abimbade S.F. \\ Department of Pure and Applied Mathematics, Ladoke Akintola University of Technology, \\ Ogbomoso, Nigeria. \\ Obalalu A.M \\ Department of Statistics and Mathematical Sciences, Kwara State University, \\ Malete, Kwara, State, Nigeria. \\ Adeosun A.T \\ Department of Mathematics, University of Ilorin, Ilorin, \\ Kwara State, Nigeria
}

\begin{abstract}
In this paper, the existence and uniqueness of Forced Convective flow through a channel with permeable walls in the presence of heat generation was investigation. The governing equation for the momentum and energy equation were non-dimensionalized using similarity transformation. In this paper the criteria that guarantee the problem has a unique solution is established.
\end{abstract}

Keywords: Forced Convective, permeable walls, unique solution.

\section{INTRODUCTION}

The investigations of forced convective hydro magnetic channel flow are importance due to its application in various manufacturing process and devices. Such flow can be found in petroleum industries, accelerator, geothermal, rocket booster.

Many scientists have contributed to the literature of forced convective [1]. [2] Studied thermal radiation and convective heating on hydro magnetic boundary layer flow of Nano fluid past a permeable stretching surface. [3] Examined the existence and uniqueness result of the problem of boundary layer flow under the action of uniform magnetic field. [4] Studied the existence and uniqueness of self-similar solution of free boundary flows in porous media with variable permeability.
In this paper, we study the problem of forced convective flow through a channel with permeable walls.

\section{PROBLEM FORMULATIONS}

We consider a steady incompressible flow of an electrically conducting variable viscosity fluid between two fixed permeable parallel infinite plates. The flow is fully developed and the edge effects are disregarded. A constant magnetic field of strength $B o$ is imposed transversely in the y-direction. The applied magnetic field is assumed to be strong enough so that the induced magnetic field due to motion is weak, It is assumed that the lower permeable plate, where fluid injection occurs is convectively heated, while at the upper permeable plate both fluid suction and convective heat loss takes place. Under these assumptions, the governing equation for the momentum equation and energy balance in one dimension can be written

As

$V \frac{d u}{d y}=-\frac{1}{\rho} \frac{d P}{d x}+\frac{1}{\rho} \frac{d}{d y}\left(\bar{\mu}(\mathrm{T}) \frac{d u}{d y}\right)-\frac{\sigma B_{0}{ }^{2} u^{2}}{\rho}$

(1) 
$V \frac{d u}{d y}=\alpha \frac{d^{2} T}{d y^{2}}+\frac{\bar{\mu}(\mathrm{T})}{\rho C_{\rho}}\left(\frac{d u}{d y}\right)^{2}+\frac{\sigma B_{0}{ }^{2} u^{2}}{\rho C_{\rho}}+\frac{Q_{0}}{\rho C_{\rho}}\left(\mathrm{T}-\mathrm{T}_{f}\right) \begin{gathered}\text { parameter } \\ \text { obspectively. Substituting equation (5) into (1)-(3) to }\end{gathered}$

(2)

The boundary conditions are

$$
\begin{array}{ll}
\mathrm{u}(0)=0, & -k \frac{d T}{d y}(0)=\gamma_{0}\left(T_{f}-T(0)\right) \\
\mathrm{u}(\mathrm{h})=0, & -k \frac{d T}{d y}(\mathrm{~h})=\gamma_{1}\left(T(\mathrm{~h})-T_{\infty}\right)
\end{array}
$$

where $(x, y)$ is the axial and normal coordinates, $u$ is the velocity of the fluid, $P$ is the fluid pressure, $V$ is the uniform suction/injection velocity at the channel walls, $\gamma_{0}$ is the heat transfer coefficient at the lower plate, $\gamma_{1}$ is the heat transfer coefficient at the upper plate, $\alpha$ is the thermal diffusivity, $\rho$ is the fluid density, $\sigma$ is the fluid electrical conductivity, $k$ is the thermal conductivity coefficient, $C_{p}$ is the specific heat at constant pressure, $T_{f}$ is the temperature of the hot fluid at the lower permeable plate, $T$ is the channel fluid temperature and $T_{\infty}$ is the ambient temperature above the upper plate. The temperature dependent viscosity is express as [6]

$$
\bar{\mu}(\mathrm{T})=\mu_{0} \ell^{-m\left(\mathrm{~T}-\mathrm{T}_{\infty}\right)}
$$

Where $m$ is a viscosity variation parameter and $\mu 0$ is the fluid dynamic viscosity at the ambient temperature.

The following non-dimensional quantities were introduced:

$G=-\frac{\partial \bar{p}}{\partial x}, \mu=\frac{\bar{\mu}}{\mu_{0}}, \alpha=\frac{k}{\rho C_{P}}, Q=\frac{Q_{0}}{\rho C_{p}}\left(\mathrm{~T}-\mathrm{T}_{f}\right), W=\frac{u}{v}, \quad X=\frac{x}{h}, \theta=\frac{T-T_{\infty}}{T_{f}-T_{\infty}}, \quad \eta=\frac{v}{h}$, $H a=\frac{\sigma B_{0}^{2} H^{2}}{\mu u}, B_{i 0}=\frac{\gamma_{0} h}{k}, B_{i 1}=\frac{\gamma_{1} h}{k}, \bar{P}=\frac{P h}{\mu_{0} V}, \varepsilon=m\left(\mathrm{~T}-\mathrm{T}_{\infty}\right), \operatorname{Pr}=\frac{v}{\alpha}, \operatorname{Re}=\frac{v h}{v}$, $E c=\frac{v^{2}}{C_{p}}\left(\mathrm{~T}_{f}-T_{\infty}\right)$

Where $\operatorname{Re}, \operatorname{Pr}, E c, \varepsilon, H a, G, Q$ are Reynolds number, Prandtl number, variable viscosity parameter, Eckertnumber, Hartmann- number, pressure gradient

$$
\frac{d^{2} \omega}{d \eta^{2}}-\varepsilon \frac{d \theta}{d \eta} \frac{d \omega}{d \eta}-e^{\varepsilon \theta}\left(\operatorname{Re} \frac{d \omega}{d \eta}+H a \omega-G\right)=0
$$

$$
\frac{d^{2} \theta}{d \eta^{2}}-\operatorname{Re} \operatorname{Pr} \frac{d \theta}{d \eta}+E c \operatorname{Pr} e^{-\varepsilon \theta}\left(\frac{d \omega}{d \eta}\right)^{2}+E c \operatorname{Pr} H a \omega^{2}+Q \theta=0
$$

With the corresponding dimensionless boundary conditions

$$
\begin{aligned}
& \omega(0)=0 \quad \text { And } \quad \omega(1)=0 \\
& \frac{d \theta}{d \eta}(0)=\mathrm{B}_{i o}(\theta(0)-1) \\
& \frac{d \theta}{d \eta}(0)=B_{i o}(\theta 1)
\end{aligned}
$$

\section{METHOD OF SOLUTION}

$$
\left(\begin{array}{l}
x_{1} \\
x_{2} \\
x_{3} \\
x_{4} \\
x_{5}
\end{array}\right)=\left(\begin{array}{l}
\eta \\
\omega \\
\theta \\
\omega^{\prime} \\
\theta^{\prime}
\end{array}\right)
$$

Differentiating (9) to obtain

$$
\begin{aligned}
& x_{4} \\
& x_{5}
\end{aligned}
$$

$\varepsilon x_{4} x_{5}+e^{\varepsilon x_{3}}\left(\operatorname{Re} x_{4}+\operatorname{Hax}_{2}-G\right)$ 
$\operatorname{Re} \operatorname{Pr} x_{5}-E c \operatorname{Pr} e^{\varepsilon x_{3}}\left(x_{4}\right)^{2}-E c \operatorname{Pr} \operatorname{Hax}_{2}^{2}+Q_{0} x_{3}$

Satisfying

the

initial

conditions $\left(\begin{array}{c}x_{1}(0) \\ x_{2}(0) \\ x_{3}(0) \\ x_{4}(0) \\ x_{5}(0)\end{array}\right)=\left(\begin{array}{l}0 \\ \omega \\ B_{i o} \\ \omega \\ B_{i 1}\end{array}\right)$

\section{EXISTENCE AND UNIQUENESS OF SOLUTION}

We state the result by (Derrick and Grossman, (1976) [5], for existence and uniqueness solution of the Initial value as follows.

Theorem 1:- Let D denote the region [in $(n+1)$ dimensional space, one dimensional for $\mathrm{t}$ and $\mathrm{n}$ dimensional for vector $\mathrm{X}]$

$$
\left|t-t_{0}\right| \leq a, \quad \| x-x_{0} \mid \leq b
$$

And suppose that $f(t, x)$ satisfies the Lipchitz condition

$$
\left\|f\left(t, x_{1}\right)-f\left(t, x_{2}\right)\right\| \angle\left\|x_{1}-x_{2}\right\|
$$

Whenever the point $(t, x-1)$ and $(t, x 2)$ belong to $\mathrm{D}$, where $\mathrm{K}$ is positive condition, Then, there is constant $\delta>0$ such that there exist a unique continuous vector solution $x(t)$ of the system.

$$
x^{\prime}=f(t, x), x\left(\mathrm{t}_{0}\right)=x_{0}
$$

In the interval $\left|\boldsymbol{t}-\boldsymbol{t}_{\mathrm{o}}\right| \leq \boldsymbol{\delta}$. Alternatively, if partial derivatives $\frac{\delta f_{i}}{\delta x_{j}}, \quad \mathrm{i}, \mathrm{j}=1,2, \ldots \ldots . \mathrm{n}$ are continuous in D. Then they are bounded on D and the condition (Derrrick and Grossman (1976)) follows the mean value theorem of differential calculus.

Theorem 2 :- Suppose $0 \leq \eta \leq 1$ are $G$, $R e, Q, \operatorname{Pr}, E c, H a, \mathcal{E}, B_{i o}, B_{i 1} \quad$ are real constant then the problem such that $w(0)=0, w(1)=0$, $\theta^{\prime}=B_{i o}(\theta(0)-1)$ and $\theta^{\prime}=B_{i o}(\theta(1)$ has a unique solution

Proof:

The system of equation can written in vector form using

$$
\left(\begin{array}{l}
x_{1}^{\prime} \\
x_{2}^{\prime} \\
x_{3}^{\prime} \\
x_{4}^{\prime} \\
x_{5}^{\prime}
\end{array}\right)=\left(\begin{array}{l}
f_{1}\left(x_{1}, x_{2}, x_{3}, x_{4}, x_{5}\right) \\
f_{2}\left(x_{1}, x_{2}, x_{3}, x_{4}, x_{5}\right) \\
f_{3}\left(x_{1}, x_{2}, x_{3}, x_{4}, x_{5}\right) \\
f_{4}\left(x_{1}, x_{2}, x_{3}, x_{4}, x_{5}\right) \\
f_{5}\left(x_{1}, x_{2}, x_{3}, x_{4}, x_{5}\right)
\end{array}\right)
$$

Subject to Initial condition(9), we show that the partial derivatives $\frac{\delta f_{i}}{\delta x_{i}} \quad$ i, $=1,2,3,4,5$ are bounded.

$$
\begin{aligned}
& \left|\frac{\partial f_{1}}{\partial x_{1}}\right|=\mathrm{O}\left|\frac{\partial f_{1}}{\partial x_{2}}\right|=\mathrm{O}\left|\frac{\partial f_{1}}{\partial x_{3}}\right|=\mathrm{O}\left|\frac{\partial f_{1}}{\partial x_{4}}\right|=\mathrm{O} \\
& \left|\frac{\partial f_{1}}{\partial x_{5}}\right|=\mathrm{O}\left|\frac{\partial f_{2}}{\partial x_{1}}\right|=\mathrm{O}\left|\frac{\partial f_{2}}{\partial x_{2}}\right|=\mathrm{O}\left|\frac{\partial f_{2}}{\partial x_{3}}\right|=\mathrm{O} \\
& \left|\frac{\partial f_{2}}{\partial x_{4}}\right|=\mathrm{O}\left|\frac{\partial f_{2}}{\partial x_{5}}\right|=\mathrm{O}\left|\frac{\partial f_{3}}{\partial x_{1}}\right|=\mathrm{O}\left|\frac{\partial f_{3}}{\partial x_{2}}\right|=\mathrm{O} \\
& \left|\frac{\partial f_{3}}{\partial x_{3}}\right|=0\left|\frac{\partial f_{3}}{\partial x_{4}}\right|=0\left|\frac{\partial f_{3}}{\partial x_{5}}\right|=0\left|\frac{\partial f_{4}}{\partial x_{1}}\right|=0 \\
& \left|\frac{\partial f_{4}}{\partial x_{2}}\right|=\left|e^{\varepsilon x_{3}} \operatorname{Hax}_{2}\right| \leq\left|\ell^{\varepsilon x_{\rho}} \boldsymbol{H a}\right| \leq \xi \mid \\
& \left|\frac{\partial f_{4}}{\partial x_{3}}\right|=\left|e^{\varepsilon x_{3}}\left(\operatorname{Re} x_{4}+\operatorname{Hax}_{2}-G\right)\right| \leq\left|e^{\varepsilon x_{\rho}}(\operatorname{Re} D+H a B-G)\right| \leq M
\end{aligned}
$$


$\left|\frac{\partial f_{4}}{\partial f_{4}}\right|=\left|\varepsilon x_{4} x_{5}+e^{\varepsilon x_{3}} \operatorname{Re} x_{4}\right| \leq\left|\varepsilon x_{5}+e^{\varepsilon x_{\rho}} \operatorname{Re}\right| \leq N$

$\left|\frac{\partial f_{4}}{\partial f_{4}}\right|=\left|\varepsilon x_{4} x_{5}\right| \leq|\varepsilon D| \leq O$

$\left|\frac{\partial f_{5}}{\partial x_{1}}\right|=\mathbf{O}$

$\left|\frac{\partial f_{5}}{\partial x_{2}}\right|=\left|-E c \operatorname{Pr} H_{a x}^{2}\right| \leq|2 E c \operatorname{Pr} H a B| \leq P$

$\left|\frac{\partial f_{5}}{\partial x_{3}}\right|=\left|-E c \operatorname{Pr} \ell^{-\varepsilon x_{3}} x_{4}^{2}-Q_{0} x_{3}\right| \leq\left|E c \operatorname{Pr} e^{-\varepsilon \rho} D^{2}-Q_{0}\right| \leq R$

$\left|\frac{\partial f_{5}}{\partial f_{4}}\right|=\left|-E c \operatorname{Pr} \ell^{-\varepsilon x_{3}} x_{4}^{2}\right| \leq\left|2 E c \operatorname{Pr} e^{-\varepsilon \rho} D\right| \leq S$

$\left|\frac{\partial f_{5}}{\partial f_{5}}\right|=\left|-\operatorname{Re} \operatorname{Pr} x_{5}\right| \leq|\operatorname{Re} \operatorname{Pr}| \leq T$

let $\mathrm{k}=\max |1, \varepsilon, \mathrm{M}, \mathrm{N}, \mathrm{O}, \mathrm{P}, \mathrm{R}, \mathrm{S}, \mathrm{T}|<\infty$. The partial derivatives, $\frac{\partial f_{i}}{\partial x_{i}} i,=1,2 \ldots n$ are bounded since there exist a constant $\mathrm{k}>0$ such that $\frac{\partial f_{i}}{\partial x_{i}} \leq k, i, j=1$, $2, \ldots \ldots . . n$ where $\mathrm{K}$ is lispchitz. Hence it satisfies a unique solution.

\section{CONCLUSION}

The boundary value problem (5) and (6) was transformed to initial value problem (10) which satisfies (11) "by Derrrick N.R and Grossman S.I [5]. Problem (10) which satisfies (11) is lipschitz continuous and hence it is bounded. The boundedness of this problem satisfies the existence of unique solution of problem (10), Hence The problem (5)(6) is unique.

\section{REFERENCES}

[1]. Prasdo Raw D.R.V, Krishna D.V and lokenath debnath (1982): combined effort of free and forced convection on MGD flow in a rotation porous channel, international of Mathematics science volume 5:165-182.

[2]. Ajala O, Adegbite P, Abimbade S.F and Obalalu A.M (2019): Thermal Radiation and Convective Heating on Hydro Magnetic Boundary Layer Flow of nanofluid Past a permeable Stretching surface,

International Journal of Applied Mathematics and science (ijamss) 2319-3972

[3]. Ajala O.A and Ayeni R.O (2008): A note on existence and uniqueness of a bounded MHD boundary layer flow, ABACUS vol 35,PP 50-55.

[4]. Ogunsola A.W and Ayeni R.O (2007): On the existence and uniqueness of self similar solutions of free boundary flows in pours media with variable permeability.ABACUS vol 34,Number 2A.

[5]. Derrrick N.R and Grossman S.I (1976): Differential equation with application, Addison wesley publishing company.

[6]. Eegunjobi A.S, Makinde O.D (2013):Entropy generation analsis in a variable viscosity MHD channel flow with Premeable walls and convective heating Mathematical3problems in Enginnering Hindawi publishing corporation 33:101 107

[7]. Ajala O.A, Obalalu A.M, Abimbade S.F and Akinyemi 0.T (2019): Numerical

study of forced convective heat generation flow through a permeable walls with suction/injection international Journal of Applied Mathematics and science (ijamss) 